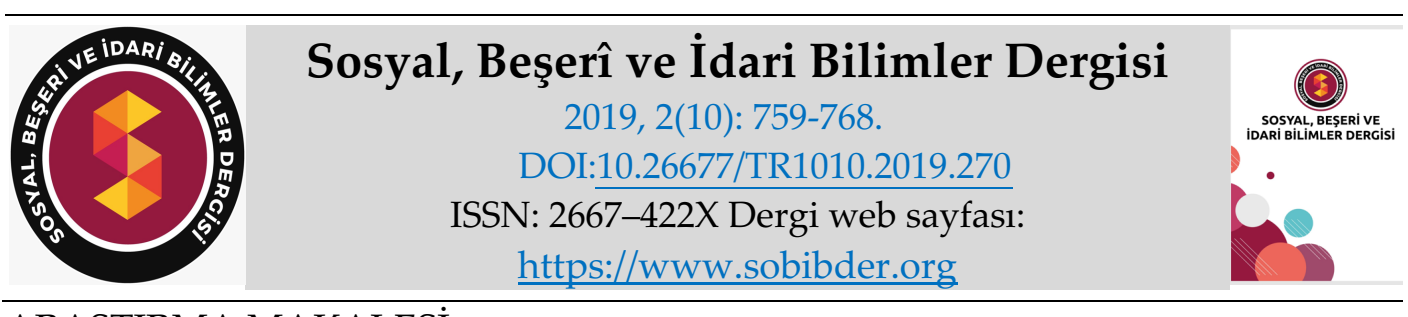

ARAȘTIRMA MAKALESI

\title{
Dilencilerin Değer Yargılarının Tespit Edilmesi ${ }^{1}$
}

Doç. Dr. Mevlüt GÜNDÜZ, Süleyman Demirel Üniversitesi, Eğitim Fakültesi, Isparta, e-posta: mevlutgunduz@sdu.edu.tr

ORCID: https://orcid.org/0000-0001-5823-190X

Arş. Gör. Ayşegül BÜYÜKKARCI, Süleyman Demirel Üniversitesi, Eğitim Fakültesi, Isparta, eposta: aysegulbuyukkarci@sdu.edu.tr

ORCID: https://orcid.org/0000-0002-0881-117X

Abdurrahman TÜRKER, Doktora Öğrencisi, Burdur Mehmet Akif Ersoy Üniversitesi, Eğitim Bilimleri Enstitüsü, Burdur, e-posta: abdurrahmanturker88@gmail.com

ORCID: https://orcid.org/0000-0002-4810-8550

Öz

Sokağa çıkıldığında çoğu yerde dilenciler ile karşılaşılmaktadır. Dilencilik toplumsal yaşamın değişmeyen özelliklerinden birisidir. Bu çalışmanın amacı, sosyal ve toplumsal bir problem olarak algılanan dilencilerin niçin dilencilik yaptıklarını araştırmaktır. Araştırmada nitel araştırma yöntemlerinden durum çalışması yöntemi kullanılmıştır. Bu araştırma 2016-2017 yılında Konya'nın Selçuklu ilçesinde 10 katılımcı ile yapılmıştır. Araştırmada veriler yarı yapılandırılmış görüşme tekniği ile elde edilmiş ve toplanan nitel verilerin analizinde betimsel analiz yaklaşımı kullanılmıştır. Dilencilerin kimler olduğunu tespit etmek ve dilenciliğin niçin yapıldığını, nasıl yürütüldüğünü, daha çok hangi ortamlarda dilendikleri belirlenmeye çalışılmıştır. Elde edilen bulgulara baktığımızda; katılımçların hasta ve mağdur durumda oldukları için dilendiklerini söylemelerine rağmen insanları kandırdıkları ve dilenciliğin onlarda alışkanlık olduğu gözlemlenmiştir. Dilencilik kolay yoldan para kazanma yöntemi olarak görüldüğü için çoğu katılımcı başka bir iş ile uğraşmayı düşünmediğini ifade etmiştir. Genellikle insanların yoğun olarak bulunduğu cadde ve sokaklarda, cami önlerinde, pazarlarda vb. yerlerde bulundukları gözlemlenmiştir.

Anahtar Kelimeler: Dilenci, Değer, Mağdur, Öksüz, Hasta

Makale Gönderme Tarihi: 05.08.2019

Makale Kabul Tarihi: 14.10.2019

\section{Önerilen Atıf:}

Gündüz, M., Büyükkarcı, A. ve Türker, A. (2019). Dilencilerin Değer Yargılarının Tespit Edilmesi, Sosyal, Beşeri ve İdari Bilimler Dergisi, 2(10): 759-768.

(C) 2019 Sosyal, Beşerî ve İdari Bilimler Dergisi.

${ }^{1}$ Bu makale, 2017 yılında Alanya'da yapılan I. Uluslararası Sınırsız Eğitim ve Araştırma Sempozyumunda özet bildiri olarak sunulmuştur. 


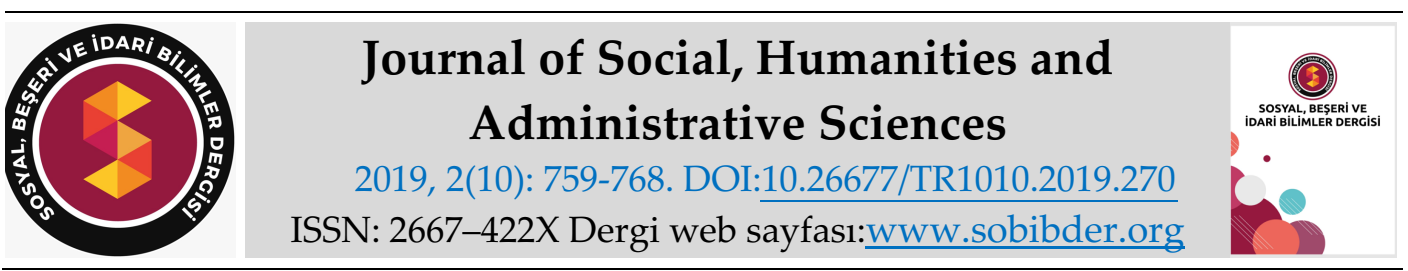

RESEARCH PAPER

\title{
Determination of Value Judgments of Beggars
}

Associate Prof. Dr. Mevlüt GÜNDÜZ, Suleyman Demirel University, Faculty of Education, Isparta, e-mail: mevlutgunduz@sdu.edu.tr ORCID: https://orcid.org/0000-0001-5823-190X

Research Assistant Ayşegül BÜYÜKKARCI, Suleyman Demirel University, Faculty of Education, Isparta, e-mail: aysegulbuyukkarci@sdu.edu.tr ORCID: https://orcid.org/0000-0002-0881-117X

Abdurrahman TÜRKER, PhD Student, Burdur Mehmet Akif Ersoy University, Institute of Educational Sciences, Burdur, e-mail: abdurrahmanturker88@gmail.com

ORCID: https://orcid.org/0000-0002-4810-8550

\begin{abstract}
We meet beggars in many streets when we go out. Begging is one of the unchangeable features of social life. The aim of this study is to search why beggars who are regarded as a social problem beg. The case study method which is one of the qualitative research methods was used in the research. This study was made with 10 participants in Selçuklu district of Konya city in 20162017. In the study, the data were obtained by semi-structured interview technique and descriptive analysis approach was used in the analysis of collected qualitative data. It has been tried to identify who the beggars are and why they are being done, how they are conducted, and in what context they are most likely to be. The research shown that they have fooled people and have observed that they are habitual in their language although participants say they are willing to be sick and victimized. Since begging is seen as an easy way to earn money, most participants have stated that they do not consider dealing with another job. It has been observed that people are usually located in streets and streets where people are concentrated, in front of mosques, in markets etc.
\end{abstract}

Keywords: Beggar, Value, Aggrieved, Orphan, Ill.

Received: 05.08.2019

Accepted: 14.10 .2019

Suggested Citation:

Gündüz, M., Büyükkarcı, A. and Türker, A. (2019). Determination of Value Judgments of Beggars, Journal of Social, Humanities and Administrative Sciences, 2(10): 759-768.

(c) 2019 Sosyal, Beşerî ve İdari Bilimler Dergisi. 


\section{GİRIŞ}

Dilenmek farklı nedenlere bağlı olarak ortaya çıkan ve insanların vicdanlarına hitap eden bazı güzel sözler söyleyerek onları etkileme yoluyla yardım isteme anlamına gelir. Bir başka deyişle dilencilik, dilenmeyi kendisine geçinme şekli olarak seçmiş (Buğra, 2008; Vatandaş, 2002) ve çevredeki insanlardan para veya eşya isteyen kimsedir.

Dilenci amacına ulaşmak maksadıyla, kişileri etkileyebilmek için istekte bulunduğu kişinin vicdanına, duygularına hitap eden sözler kullanır veya davranışlar gösterir (Köktürk, 2008; Kükrer, 2014; Gürbüz, 2014). Bu durum dilenciyle karşılaşan kişilerde her zaman vicdani bir sorgulama yapma gereği hissettirir.

Munzer'e göre dilenci; çalışmak ya da kendisine sunulmuş diğer yolları değerlendirmek yerine para ya da malları kabul etmeye hazır kişiyi ifade etmektedir (Munzer, 2001: 48). Goel de dilenciliği sosyolojik bakışla, yoksulluk ve evsizliğin ortaya çıkardığı derin sosyal ve politik problemlerin bir yansıması olarak değerlendirmiştir (Goel, 2010: 32). Dilenci ile ilgili Literatürde ortaya konulan her tanımın daha da geliştirilip ayrıntılandırılması mümkündür.

Toplumdaki bazı bireyler farklı nedenlerden ötürü dilencilik yapmaktadırlar. Bu nedenler, bireysel ve toplumsal olarak nitelendirilebilir (Solinger, 2001). Ülkenin ekonomik şartlarının yeterli düzeyde olmamasına bağlı olarak bireylerin ekonomik olarak etkilenmesi ve yaşamlarını sürdürmede zorluk çekmesi toplumsal neden olarak gösterilebilir. Bireysel nedenler ise kişinin özel durumu, sahip olunan özel ekonomik koşullar olarak ifade edilebilir. Bazı bireyler ise ekonomik getirisinin yüksekliğinin teşvik edici etkisiyle de dilenciliğe yönelebilmektedir.

Dilenciliğe, farklı yerlerde ve farklı zamanlarda dolayısıyla da her yerde rastlayabiliriz. Özellikle dini duyguların yoğunlaştığı zaman ve mekânlarda daha sık rastlanılmaktadır. Zaman olarak daha çok Ramazan ayları, Cuma günleri, Kandil gün ve geceleri; mekân olarak da mezarlar, türbeler, cami önleri vb. bu iş için daha çok tercih edilmektedir (Gürbüz, 2014; Akça, 2008). Ayrıca insanların yoğun olarak bulunduğu belirli cadde ve sokaklar, hastane önleri, pazarlar vb. yerlerde de sık sık karşımıza çıkmaktadır.

İnsanlar gerek dini nedenlerden ötürü gerekse sahip olduğu hümanist kişilik yapısıyla diğer insanlara yardım etmekten mutluluk duyarlar. Yardımseverlik aslında bu yönüyle de evrensel bir değer olarak da karşımıza çıkmaktadır. Ancak kişilerin bu insani yönü zaman zaman bazı nedenlerden dolayı istismar edilmektedir (Doğan, 2015).

Bu durum aslında toplumsal olarak insanların geldiği durumu göstermektedir. Güvenin olmadı bir toplum yapısında insanlar yardım ederken bile şüpheye düşmeye başlamaktadır. Neticede insanın bu yardımsever olma duygusu karşıdaki insanlar tarafından veya dilenciler tarafından kötü amaçla kullanılsa bile manevi dönüt olarak nasıl olsa bana yansıması olur düşüncesiyle yine de devam etmektedir. İnsanoğlunun ahlaki ikilem yaşamasına rağmen bu özelliğini devam ettirmesinin olumlu mu yoksa olumsuz bir davranış olduğu tartışılmaktadır. Diğer bir açıdan bu olayı kişinin kendi bünyesinde barındırdığı değer yargılarıyla ilişkilendirebiliriz.

Bazı insanlar manevi açıdan bana bu dilenciyi Allah gönderdi yardım etmem lazım düşüncesine sahipken bazıları da bu bir sadaka, beni kazadan beladan korur anlayışına sahip olabilmektedir (Vatandaş, 2004). Bu durum kişinin olaya dini açıdan bakarak bazı değerler kapsamında olayı değerlendirdiğini göstermektedir. Yine bazı insanlar da dilenen kişiler için, gerçekten ihtiyacı olsa alın teri ile çalışarak kazanır veya en azından bir şeyler satar düşüncesine sahiptir. Böyle bir değerlendirme yapan insan da yine kendi sahip olduğu değer yargıları açısından açgözlü insanlara ders verilmesi gerektiğine inanabilmektedir. Dilencilere karşı bu şekilde farklı davranışlar sergilemenin altında insanların sahip oldukları değer yargılarının olduğunu düşünebiliriz. 
Değer, insanlar için önemli olan her türlü bakış açısı, olgu ya da tutumlardır. Genellikle insanların sahip olduğu tek bir değerden söz etmek çok zordur. Çünkü insanlar her olaya bir farklı bir değer yargısıyla yaklaşmaktadır. Değerler birbirleri ile sürekli etkileşim içinde bulunur ve birbirlerinden etkilenen bir yapıya sahiptir. Dilencilere karşı insanların sergiledikleri durum da değer algısıyla yakından alakalıdır. Yine dilenciler insanların bu değer yargılarını çok iyi bildikleri için bunu farklı maksatlarla da kullanabilmektedir.

Dilencilik bu nedenlerden ötürü maksadı değişse de "yardımseverliği" üstün bir değer olarak gören toplumlarda görülmekte ve görülmeye de devam edecektir (Wassan ve Khuro, 2011). Dilenciler, insanların kendilerine yardımda bulunmalarını sağlamak için, istekte bulunduğu kişinin vicdanına, duygularına hitap eden sözler kullanır veya tavırlar sergiler. İnsanlar yardıma muhtaç olduğuna inanmasalar bile vicdanlarını rahatlatmak için dilencilere yardım etmektedirler. Çünkü dilencinin özellikle fiziksel görünümünden (özründen, sakatlığından) çok etkilenmektedirler.

Dilenciler; yoksul, düşkün, sakat numaraları yaparak, kişilerin dini duygularına hitap eden kelimeler kullanarak, insanların yardımseverlik duygularını kullanmayı alışkanlık haline getirmekte ve bu şekilde insanları kandırarak kolay yoldan para kazanmaktadırlar (Vatandaş, 2002).

$\mathrm{Bu}$ gibi nedenlerden ötürü araştırmanın amacı, dilencilerin yaptıkları işe yönelik değer yargılarını ve tutumlarını ortaya çıkarmaktır. Böylelikle de toplumsal bir farkındalık oluşturularak toplumun bakış açısına katkı getireceği beklenmektedir.

\section{YÖNTEM}

Araştırmada nitel araştırma yöntemlerinden durum çalışması yöntemi kullanılmıştır. Durum çalışması, tek bir kişinin, bir ortamın, tek bir tür dokümanın ve olayın ayrıntılı olarak incelenmesidir (Kazak, 2001:146).

Bu araştırma, 2016-2017 yılında Konya ilinin Selçuklu ilçesinde bulunan 10 dilenci ile bir miktar para karşıllğında; pazarda, sokaklarda ve cami önlerinde yüz yüze görüşülerek gerçekleştirilmiştir.

Araştırmada veriler yarı yapılandırılmış görüşme tekniği ile elde edilmiştir. Yarı-yapılandırılmış görüşmeler için, tüm görüşmelerde kullanılmak üzere bir dizi soru hazırlanır. Kendileriyle görüşülen kişilerin hepsine sorular ayn sırayla sorulur; ancak, kendisiyle görüşülen kişinin görüşme sırasında soruları istediği genişlikte yanıtlamasına izin verilir (Ekiz, 2003).

Görüşmeler 3 ile 5 dakikalık zaman diliminde gerçekleştirilmiştir. Görüşmeler sırasında ses kayıt cihazı kullanımı için görüşülen kişinin izni alınmış ve bütün konuşmalar kayıt altına alınmıştır. Araştırmanın güvenirliğini artırmak için kullanılan stratejinin nasıl kullanıldığı belirgin halde verilmiş ve bu şekilde diğer araştırmacıların da bu stratejiyi benzer bir biçimde kullanabilmesine olanak tanıması öngörülmüştür (Silverman, 2000; Yıldırım ve Şimşek, 2005).

Toplanan nitel verilerin analizinde betimsel analiz yaklaşımı kullanılmıştır. Betimsel analizde, görüşülen dilencilerin görüşlerini çarpıcı bir biçimde yansıtmak amacıyla doğrudan alıntılara çok defa yer verilmiştir. Betimsel analiz yapılmasındaki amaç, elde edilen bulguları düzenleyerek yorumlamak ve anlam bütünlüğü içinde okuyucuya sunmaktır. 


\section{BULGULAR ve YORUM}

Dilencilerin toplumun değerine bakış açısını incelemek amacıyla yapılan bu çalışmada dilenciler ile tek tek görüşülüp düşünceleri ortaya konmuş, daha sonra da ilginç olan ifadeler aynen sunulma yoluna gidilmiştir.

\section{Kendileriyle görüşülen dilencilerin "Niye dileniyorsun? "şeklindeki soruya verdikleri cevaplar incelendiğinde 1 . bulgu şöyledir:}

Katılımclar genellikle yoksul ve mağdur olmaları, öksüz torunlarının olması, bakmak ile yükümlü olduğu kardeşleri olduğu için dilendiklerini ifade etmişlerdir. On kişiden dokuzu kendisinin veya ailesinden herhangi biri hasta olduğu için dilendiğini belirtmiştir. Bu hastalıklarının da çalışmalarına engel olduğu için dilendiklerini dile getirmişlerdir. Bu soruyla ilgili 2. Dilencinin görüşü aynen şu şekildedir:

"Varlığım olmadığı için dileniyorum. Devlet hiç yardım etmiyor 3 aydan 3 aya bir maaş veriyor oda yetmiyor. Evim kira, kardeşlerim öksüz, annem hasta onlara bakıyorum. Kendim de hastayım çalışacak durumda değilim. Halktan topluyorum veren olursa alyyorum veren olmazsa çekip gidiyorum."

Bu soruyla ilgili 5. Dilencinin görüşü aynen şu şekildedir:

“Maddi durumum iyi değil, tüpüm boş, evimde yiyeceğim yok, ekmeğim bile yok yani. (elinde de sigara vardi.)"

Bu soruyla ilgili 8. Dilencinin görüşü aynen şu şekildedir:

“Oğullarım ceza evinde. Mağdurum, evim yok, yoksulluktan dilencilik yapiyorum."

Bu soruyla ilgili 9. Dilencinin görüşü aynen şu şekildedir:

"Dulum, bakacak kimsem yok onun için dileniyorum. Eşim öleli 4 sene oldu.

Odunum kömürüm yok onu alacam."

Katılımcılar, dilenme sebeplerini daha çok yoksulluğu nedeniyle hastalığını tedavi ettiremediğini ve tedavi olabilmek için, hastalığı/sakatlığı nedeniyle çalışamadığından yaşamını sürdürebilmek için dilenmek zorunda kaldıklarını dile getirmişlerdir. Bazıları ise hasta olduklarını kanıtlamak amacıyla sağlık raporu kullanmakta olduğunu göstermiştir. Bir katılımcı ayaklarından rahatsız olduğu için tekerlekli sandalye kullandığı, bir katılımcının da görme engelli olduğu için dilendiği gözlemlenmiştir.

Kendileriyle görüşülen dilencilerin "Belli bir süre sonra alışkanlığa mı dönüşüyor?" şeklindeki soruya verdikleri cevaplar incelendiğinde 2. bulgu şöyledir:

Alışkanlık olmadığı mağdur durumda oldukları için dilendiklerini ve yaşları dolayısıyla başka bir iş yapamadıkları için mecburen bu işi yaptıklarını belirtmişlerdir. Bazıları da önce başka işlerle uğraştıklarını ama artık o işi yapamadıkları için dilencilik yaptıklarını dile getirmiştir. Bu soruyla ilgili 9. Dilencinin görüşü aynen şu şekildedir:

"Hayır, ben önce bohça satıyordum zaten dilenmeyi sevmem. Mecbur olunca, beyim ölünce çıkıyorum. Dul kartım da var. Dilenmeyi sevmem ama başka ne yapıyım bu yaştan sonra hırsızlık mı yapıyım. Çaresizlik yüzünden çıktım."

Bu soruyla ilgili 7. Dilencinin görüşü aynen şu şekildedir:

"Her zaman gelmem Cuma'dan cumaya gelirim. Ben evlendikten sonra başladım. Çocuklara ekmek parası götürüyorum" 
Bu soruyla ilgili 3. Dilencinin görüşü aynen şu şekildedir:

"Meraklısı heveslisi değilim. Allah doğruluktan versin. Oğlum var Tekirdağ da askerlik yapıyor. 350 lira kira ödüyorum. Bir tane de torunuma bakıyorum."

Bu soruyla ilgili 10. Dilencinin görüşü aynen şu şekildedir:

"Hayır, benim oğlum hapiste bakanım yok onun için dileniyorum."

Bütün katılımcılar, bu mesleğin onlarda alışkanlığa dönüşmediğini mecburiyetten yaptıklarını belirtmiştir. Bazı katılımcılar da işleri olsa dahi bazı sebeplerden dolayı çalışamayacaklarını dile getirmiştir.

Kendileriyle görüşülen dilencilerin "Kişiye göre mi istiyorsunuz?" şeklindeki soruya verdikleri cevaplar incelendiğinde 3 . bulgu şöyledir:

Katılımclar kişiye göre ayırt etmediklerini herkesten aynı şekilde istediklerini ifade etmişlerdir. Bu soruyla ilgili 1. Dilencinin görüşü aynen şu şekildedir:

"Kendileri gelip para veriyor ben istemiyorum. Seven sayan insanlar biliyor mağdur durumda olduğumu. Kaç senedir burada duruyorum ben zaten."

Bu soruyla ilgili 5. Dilencinin görüşü aynen şu şekildedir:

“Ben ilahi söyleyerek giderim kimseden zorla almam."

Bu soruyla ilgili 7. Dilencinin görüşü aynen şu şekildedir:

"Herkesten isterim. Evlerde bildiğim tanıdığım kişiye giderim."

Bu soruyla ilgili 8. Dilencinin görüşü aynen şu şekildedir:

"Hayır. Verdikleri ile bir ekmek alırım giderim vermezlerse oda yok."

Bazı katılımcıların ise her gün aynı yerde durduğu için çevredeki insanlar tarafından tanınıp sürekli yardımda bulunulduğunu söylemiştir.

Kendileriyle görüşülen dilencilerin “İnsanları kandırıyor musunuz?" şeklindeki soruya verdikleri cevaplar incelendiğinde 4 . bulgu şöyledir:

Bütün katılımcılar insanları kandırmadıklarını belirtmiştir. Bazı katılımcılar doğru söylediğine inandırmak için evine davet ettiği bile olmuştur. Bu soruyla ilgili 6. Dilencinin görüşü aynen şu şekildedir:

"Niye kandırayım. Kandıracak bir durumum yok evimi gelip gören de oldu."

Bu soruyla ilgili 1. Dilencinin görüşü aynen şu şekildedir:

“Hayır, kandırma falan yok bir gün satmayım sabah ekmek parası bulamam komşuya giderim ödünç 5 lira alırım komşu da verir zaten tekrar parayı getireceğimi bilir."

Bu soruyla ilgili 3. Dilencinin görüşü aynen şu şekildedir:

"Duygu sömürüsü gibi geliyor insanlara ama Allah doğruluktan versin. Öle kişilerde var yani ama ben kandırmıyorum."

Bu soruyla ilgili 10. Dilencinin görüşü aynen şu şekildedir:

“Hayır, ekmek çarpsın ki kandırmıyorum. Oğlum evde olsun ben dilenmem. Mecburum vallahi dün ekmek parası yoktu. Bir komşudan 20 lira aldım dün onunla geçindim. Bakanım yok. Gelin evime de bakabilirsiniz" 
Genel olarak kandırmıyorum ifadelerini kullansalar da konuşurken bazılarının insanları kandırdığı görülmüştür. Bir katılımcının ise yiyecek ekmeğinin dahi olmadığını ifade ederken sigara içtiği gözlemlenmiştir. Başka bir katılımcı da önce 4 torununun öksüz olduğunu onlara baktığını, daha sonraise 5 torunu olduğunu ifade etmiştir.

Kendileriyle görüşülen dilencilerin “Günlük ne kadar kazanıyorsunuz?" şeklindeki soruya verdikleri cevaplar incelendiğinde 5 . bulgu şöyledir:

Katılımcılar ortalama olarak 30-40 lira civarında kazandıklarını belirtmiştir. Ne kadar kazandıklarını üst üste ısrar edilerek tekrar tekrar sorulduğunda, her seferinde kazandıkları miktarı arttırdıkları görülmüştür. Bu durum söyledikleri cevapların çok da güvenilir olmadığını ve kazancının bilinmemesini istediklerini göstermektedir.

Kendileriyle görüşülen dilencilerin “Hangi ortamlarda daha çok dileniyorsunuz?" şeklindeki soruya verdikleri cevaplar incelendiğinde 6 . bulgu şöyledir:

İnsanların yoğun olarak bulunduğu cadde ve sokaklarda, semt pazarlarında, hastane önlerinde, cami önlerinde, alt ve üst geçitlerde daha çok bulunduklarını belirtmişlerdir. Bazıları da evleri ve dükkânları gezdiğini belirtmiştir. Bu soruyla ilgili 7. dilencinin görüşü aynen şu şekildedir:

“Ben sürekli apartmanları gezerim. Cami önüne dururum bide."

Bu soruyla ilgili 9. dilencinin görüşü aynen şu şekildedir:

"Ben burada oturmuyorum bozkır da oturuyorum. Buraya iki üç günlüğüne geldim sonra gideceğim."

Bu soruyla ilgili 3. dilencinin görüşü aynen şu şekildedir:

"Semt pazarları, hastane önleri"

Bu soruyla ilgili 1. dilencinin görüşü aynen şu şekildedir:

"Nalçacı da cadde üzerinde duruyorum. Hastayım başka bir yere gidemem gezemem o yüzden sadece burada dileniyorum."

Katılımclar, dilenme mekânlarını seçerken, geçiş alanının dar olduğu yerleri özellikle seçtiklerini (Dean ve Gale, 1999) ve daha çok kişinin kendisiyle karşılaşmasını sağladıklarını ve bu durumunda yardım edenlerin sayısında artış sağladığını dile getirmişlerdir.

Kendileriyle görüşülen dilencilerin "Sizi bu mesleğe ne itti?" şeklindeki soruya verdikleri cevaplar incelendiğinde 7. bulgu şöyledir:

Katılımclar yoksulluktan, para olmayınca başka ne yapalım, hastalık beni bu mesleğe itti gibi ifadeler kullanmışlardır. Bu soruyla ilgili 5. dilencinin görüşü aynen şu şekildedir:

"Yoksulluk evde yiyeceğim olsa ekmeğim olsa gelir miyim hiç buralara. 55 yaşında hasta bir adamim ben."

Bu soruyla ilgili 3. dilencinin görüşü aynen şu şekildedir:

“Hastalığım itti. Devlet itti. Kaymakamlığa gidiyorum çalışır vaziyette görüyorlar beni git çalış diyorlar. Sigortam yok hiçbir şeyim yok devlet bana sadece kömür veriyor. Suriyelilere öncelik taniyorlar sen git Suriyeli gelsin diyorlar."

Bu soruyla ilgili 9. dilencinin görüşü aynen şu şekildedir:

"Para olmayınca ne yapalım hırsızlık mı yapalım. Mecbur kalınca çıkıyoruz işte."

Bu soruyla ilgili 4. dilencinin görüşü aynen şu şekildedir: 
“25-30 sene tarlalarda orak biçtim. Ama şimdi gücüm yok gidemiyorum. Aylığım yok."

Dilencilerin büyük çoğunluğu aslında çalışabilir durumda olduğu halde çeşitli bahaneler ileri sürmüştür. Katılımcılar, çalışacak kendilerinden başka kimse olmadığını ifade etmişlerdir. Bazı katılımcılar da çocukluktan beri dilencilik yaptığını ifade etmiştir.

Kendileriyle görüşülen dilencilerin “Hedefiniz ne?" şeklindeki soruya verdikleri cevaplar incelendiğinde 8 . bulgu şöyledir:

7 katılımcı herhangi bir hedefinin olmadığını belirtmiştir. Bir katılımcı hırdavat malzemesi alıp pazarlarda tezgâh açmayı düşündüğünü, diğer katılımcı seyyar satıcılık yapmayı düşündüğünü belirtmiştir. Başka bir katılımcı ise kızının kanser hastası olduğunu ve onu bu hastalıktan kurtarmak istediğini ifade etmiştir.

Katılımcılar her ne kadar inkâr etseler de dilencilik çoğunda alışkanlık haline gelmiştir. Çoğu katılımcının kullandığı cümleler, davranış şekilleri, yaşam hikâyeleri birbirine benzer özellikte olduğunun farkına varılmıştır. Bazı dilenciler, araştırmacının yalan söylediğini; polis, savcı, zabıta veya haberci olduğunu düşünerek konuşmak istemediği belirtmiş ve hatta bazılarının kaçıp gittiği görülmüştür. Konuşulan katılımcıların ise konuşulduktan sonra bulunduğu yerden ayrıldığı görülmüştür.

Soruları cevaplamayı kabul eden bazı katılımcılar ses kayıtlarının veya görüntülerinin bir yerde kullanılacağını düşünerek, 'eğer bunları bir yerde kullanırsan öbür dünya da iki elim yakanda olur.' gibi ifadeler kullanarak bedduada bulundukları gözlemlenmiştir.

Dilencilerin, sözleri ve hareketleri ile yardımseverlerin doğrudan vicdanlarına, duygularına hitap etme yöntemlerini uyguladıkları tespit edilmiştir. Maalesef, bilindiği kadarıyla, kişiyi yardıma sevk etmenin en kolay ve sonuç veren yönteminin bu olduğu düşünülebilir. Hatta dilencilere para vermenin sevap kazandıracağı düşüncesi, dilenciliğin örgütlü biçimde bir sektör olarak faaliyetine devam etmesine ve büyümesine neden olmaktadır (Wassan ve Khuro, 2011).

\section{SONUÇ ve TARTIŞMA}

Araştırmadan elde edilen bulgular neticesinde, dilencilerin çoğu muhtaç durumda olduklarını ifade etseler de dilenciliğin birçok dilenci tarafından hem bir meslek hem de bir alışkanlık olarak algılandığ tespit edilmiştir (Buğra, 2008; Demirtaş, 2006; Vatandaş, 2002). Dilencilerin söylemlerinin aksine dilencilerin yalnızca küçük bir kesiminin yoksulluk nedeniyle dilendiği düşünülmüştür.

Dilenciliğin ekonomik getirisinin yüksekliği (Vatandaş, 2002), teşvik edici unsurların başında yer almaktadır. Dilenciliğin kolay bir iş olarak görülmesi ve dilenmeye eğilimli insanlar için teşvik edici bir özellik olarak anlam kazanabilmektedir (Vatandaş, 2002).

Dilencilik için önemli hususlardan biri de dilenme yöntemidir. Hastalık raporları, annelik rolünü kullanma, vicdani sözler kullanma, güzel dualar etme, yaşlılık ve sakatlık olgusu, sert ve soğuk iklim koşullarıyla tezat oluşturan kıyafetlerle dolaşma, eski kıyafetler giyme gibi yöntemler dilencilerin en çok başvurdukları yöntem olarak tespit edilmiştir (Parin, 2010; Demirtaş, 2006).

Dilencilerin dilenme mekânları olarak daha çok alt veya üst geçitleri, camileri, pazarları ve insanların yoğun olarak bulunduğu sokakları daha çok tercih ettikleri görülmüştür. Sokaklarda genel olarak 50 ile 70 yaş arası dilenci sayısının daha çok olduğu gözlemlenmiştir. Yardımda bulunan vatandaşların yaşlı insanlara daha çok yardım ettikleri tespit edilmiştir (Köktürk, 2008). 
Dilencilerde bir diğer gözlenen durum ise çoğunun, başlarını öne ya da yana eğerek ellerini açıp istekte bulunmalarıdır. Dilenciler, muhatabının durumuna göre, "Allah rızası için fakire bir sadaka", "Allah işini rast getirsin", "Allah sevdiğine kavuştursun", "Allah evladını bağışlasın" gibi beklenen dilenme cümlelerini sıklıkla tekrar etmektedirler. İnsanlardan bir şey talep eden dilencinin, kötü muameleye tahammül edemediği, bazen dilencinin, adeta, karşısındaki kişiden kötü söz işitmektense hiçbir şey vermemesini tercih ettiği görülmüştür (Dikmen ve Çetin, 2008).

Bu çalışma göstermiştir ki dilenciler mecburiyetten bu işi yaptıklarını söylese de insanlar her ne kadar dilencilere kızsa da yine de hümanist tavırlarla yardım etmeye devam edebilecekleri görülmektedir. Durum böyle olunca da dilencilik işi bir şekilde devam etmeye mahkûmdur (Wassan ve Khuro, 2011).

Dilenciler açısından ise insanların hassas duygularını, merhametlerini, yardım severliliklerini ve duyarlılıklarını çok iyi bildikleri için bunu kullanmaktadırlar. Nitekim dilencilerin söylediklerinden anlaşıldığı üzere, dilencilik daha çok olumsuz değer yargılarının bütünleşmiş hali olarak değerlendirilebilir (Massey vd., 2010).

\section{KAYNAKÇA}

Akça, Ü. (2008). Sosyal Dışlanma ve Arınma Arasında Dilencilik, Bir Kent Sorunu DilencilikSorunlar ve Çözüm Yolları Sempozyumu, (Yay. Haz. Suvat Parin), 18-19 Ekim, İstanbul

Buğra, A. (2008). Kapitalizm, Yoksulluk ve Türkiye'de Sosyal Politika, İstanbul: İletişim.

Dean, H. and Gale, K. (1999). Begging and the Contradictions of Citizenship, Dean, H. (der.), Begging Questions: Street-Level Economic Activity and Social Policy Failure içinde, Bristol: Policy Press

Demirtaş, M. (2006). Osmanlı Başkent'inde Dilenciler ve Dilencilerin Toplum Hayatına Etkileri, OTAM Ankara Üniversitesi Osmanlı Tarihi Araştırma ve Uygulama Merkezi Dergisi, 20, 81-104

Dikmen, M. ve Çetin, K. (2008). Dilenciliğin Türk Şiirindeki Tezahürleri, Bir Kent Sorunu: Dilencilik "Sorunlar ve Çözüm Yolları, İstanbul: İstanbul Büyükşehir Belediyesi Zabıta Daire Başkanlığı Yayınları

Doğan, C. (2015). Kırım Harbi'nden I. Dünya Savaşına İstanbul'da Dilencilik Olgusuna Bir Bakış (1853- 1914), Avrasya Uluslararası Araştırmalar Dergisi, 3(6), 151-173

Ekiz, D. (2003). Eğitimde Araştırma Yöntem ve Metotlarına Giriş, Ankara: Anı Yayıncılık

Goel, A. (2010). Indian Anti-Beggary Laws and Their Constitutionality Through the Prism of Fundamental Rights with Special Reference to Ram Lakhan V. State, Asia Pacific Journal on Human Rights and the Law, 11(1), 23-38

Gürbüz, A. (2014). Reşat Nuri Güntekin'in Miskinler Tekkesi Romanında Dilencilik Algısı, Turkish Studies, 9(3), 745-754.

Kazak, N. (2001). Sosyal Bilimlerde Araştırma Yöntemleri, Eskişehir: Anadolu Üniversitesi Yayınları

Köktürk, M. (2008), Bir Bilinç Durumu Olarak Dilencilik" Bir Kent Sorunu: Dilencilik Sempozyumu Tebliğler Kitabı (ed: Suvat Parin). İstanbul: İBB Zabıta Daire Başkanlığı, 397-411

Kükrer, M. (2014). Ankara'da Dilencilik ve Sadaka Kültürü, Ankara Üniversitesi, Yayınlanmamış Yüksek Lisans Tezi, Ankara.

Massey, D., Abdur, R. and Janet, S. (2010). Begging in Rural India and Bangladesh, EPW Economic \& Political Weekly, 45(14), 64-71 
Munzer, S. R. (2001). Heroism, Spiritual Development, and Triadic Bonds in Jain and Christian Mendicancy and Almsgiving, International Journal of the History of Religions, 48(1), 47-80

Parin, S. (2010). Dilencilik Yoksulluk İlişkisi, Sosyoloji Dergisi, 3 (20), 23-37

Silverman, D. (2000). Doing Qualitative Research: A Practical Handbook. London: Sage.

Solinger, R. (2001). Beggars and Choosers: How the Politics of Choice Shapes Adoption, Abortion and Welfare in the United States, New York: Hill and Wang

Vatandaş, C. (2002). Dilenciler ve Dilencilik (Sosyolojik Bir Araştırma), AKÜ Sosyal Bilimler Dergisi, 4(1),170-183

Vatandaş, C. (2004). Toplumsal Bir Değer Olarak Yardımlaşma ve Dilenciler, Afyon Kocatepe Üniversitesi Sosyal Bilimler Dergisi, 5(1), 149-160

Wassan, A.A. and Khuro, S. (2011), Beggary in District Sanghar: A Sociological Analysis of Shahdadpur, Tandoadamand Sinjhoro Subdivisions, New Horizons, 5(2), 28-39

Yıldırım, A ve Şimşek, H. (2005). Sosyal Bilimlerde Nitel Araştırma Teknikleri, Ankara: Seçkin Yayınları 